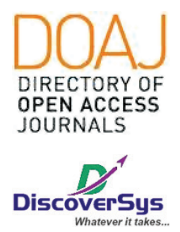

Published by DiscoverSys

\title{
Perbedaan cost-effectiveness pengangkatan drain kurang dari 3 hari dengan lebih dari 3 hari pada modified radical mastectomy
}

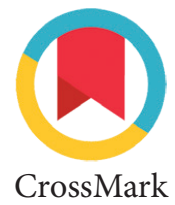

\author{
Dewa Nyoman Putra Adiwinata, ${ }^{1 *}$ Ketut Widiana $^{2}$ I Gde Raka Widiana ${ }^{3}$
}

\section{ABSTRACT}

Introduction: Modified radical mastectomy (MRM) is a therapeutic choice for operable breast cancer. The most frequent post-surgery complication is seroma formation, and this can be circumvented by the use of drainage. There is still a debate over the use of drainage time on the effectiveness and cost efficiency used. The purpose of this study is a more in-depth study of the cost-effectiveness of removing drainage in less than three days with more than three days, in patients post-MRM.

Method: This research is a cost-effectiveness analysis using a decision tree, with a cross sectional analytic research design. Data collection was performed retrospectively by comparing direct medical cost to evaluate the difference in cost-effectiveness of drain removal for less than three days and for more than three days for modified radical mastectomy (MRM).

Results: 36 samples were collected that met the exclusion and inclusion criteria, consisting of 19 samples in the group with drain removal $\leq 3$ days, and 17 samples in the group with drain removal $>3$ days. Analysis of the cost of removing the drain less than three days showed the average direct medical cost of the patient was Rp. 700,578.00. Whereas patients with drain removal for more than three days showed a direct medical cost of Rp. $981,000.00$. The average difference in average cost-effectiveness ratio between the two groups is $\mathrm{Rp} .2,599.00$.

Conclusion: In this study, patients with drain removal $\leq 3$ days had better cost-effectiveness compared to drain removal $>3$ days.

Keywords: cost, effective, drain, post-operation.

Cite This Article: Adiwinata, D.N.P., Widiana, K., Widiana, I.G.R. 2020. Perbedaan cost-effectiveness pengangkatan drain kurang dari 3 hari dengan lebih dari 3 hari pada modified radical mastectomy. Intisari Sains Medis 11(2): 556-560. D0I: 10.15562/ism.v11i2.720

\section{ABSTRAK}

Pendahuluan: Modified radical mastectomy (MRM) adalah pilihan terapi pada kanker payudara dapat dioperasi. Komplikasi pasca tindakan yang paling sering terjadi adalah terbentukya seroma, dan hal tersebut dapat disiasati dengan penggunaan drain. Masih terjadi suatu perdebatan terhadap lama pemakian drain terhadap efektifitas dan efisiensi biaya yang digunakan. Tujuan dari penelitian ini adalah pengkajian lebih mendalam tentang cost-effectiveness pada pengangkatan drain kurang dari tiga hari dengan lebih dari tiga hari, pada pasien pasca tindakan MRM

Metode: Penelitian ini merupakan penelitian cost-effectivness analisis menggunakan decision tree, dengan rancangan metode penelitian analytic cross sectional. Pengambilan data dilakukan secara retrospektif dengan membandingkan direct medical cost (biaya medis langsung) untuk mengevaluasi perbedaaan cost-effectiveness pengangkatan drain kurang dari tiga hari dan lebih dari tiga hari pada modified radical mastectomy (MRM).

Hasil: Dikumpulkan 36 sampel yang memenuhi kriteria ekslusi dan inklusi, terdiri dari 19 sampel pada kelompok dengan pengangkatan drain $\leq 3$ hari, dan 17 sampel pada kelompok dengan pengangkatan drain $>3$ hari. Analisis biaya pada pengangkatan drain yang kurang dari tiga hari menunjukkan rerata direct medical cost pasien adalah Rp. 700,578,00. Sedangkan untuk pasien dengan pengangkatan drain lebih dari toga hari menunjukkan direct medical cost sebesar Rp. $981.000,00$. Rerata perbedaan average cost-effectiveness ratio antara kedua kelompok adalah Rp. 2,599,00.

Simpulan: Pada penelitian ini didapatkan pasien dengan pengangkatan drain $\leq 3$ hari memiliki cost-effectiveness lebih baik dibandingkan dengan pengangkatan drain $>3$ hari.
*Correspondence to: Dewa Nyoman Putra Adiwinata, PPDS-1 IImu Bedah, Fakultas Kedokteran Universitas UdayanaRSUP Sanglah Denpasar, BaliIndonesia

f0.95noctilux@gmail.com

Diterima: $24-02-2020$

Disetujui: $15-06-2020$

Diterbitkan: 11-07-2020
Kata kunci: biaya, efektif, drain, pasca operasi.

Cite Pasal Ini: Adiwinata, D.N.P., Widiana, K., Widiana, I.G.R. 2020. Perbedaan cost-effectiveness pengangkatan drain kurang dari 3 hari dengan lebih dari 3 hari pada modified radical mastectomy. Intisari Sains Medis 11(2): 556-560. D0I: 10.15562/ism.v11i2.720

\section{PENDAHULUAN}

Kanker payudara merupakan penyakit keganasan paling sering didiagnosis dan penyebab umum kedua terkait kematian akibat kanker pada wanita di seluruh Dunia. Tindakan pembedahan sebagai modalitas terapi utama pada kanker payudara, dan modified radical mastectomy (MRM) adalah 
pilihan terapi pada kanker payudara dapat dioperasi. Komplikasi pasca operasi dapat terjadi hematoma, terbentuknya seroma, infeksi luka operasi, hingga terbentuknya flap nekrosis. ${ }^{1}$

Seroma sering terjadi setelah tindakan MRM, dan banyak ahli bedah mengatakan terbentuknya seroma merupakan hal paling sulit dicegah dibandingkan komplikasi lain. Seroma didefinisikan sebagai cairan serous setelah pembedahan, terbentuk di bawah flap kulit dan mengisi dead space. Setelah MRM, seroma akan terkumpul di daerah bawah kulit dan dead space di daerah aksila. Biasanya seroma akan diserap sendiri dalam beberapa minggu. Jika cairan seroma sangat banyak, kulit bekas operasi akan tegang. Pada beberapa pasien penumpukan cairan ini akan memberi masalah, seperti memperlama hari perawatan dan akan menambah biaya perawatan. Selain itu, penyedotan seroma berulang kali akan menyebabkan pasien merasa tidak nyaman. ${ }^{2}$

Setelah operasi, drain akan dipasang untuk mengalirkan seroma, tapi tidak untuk mencegah terbentuknya seroma. Drainase dapat berupa suction drain atau drain pasif, masing-masing mempunyai kekurangan dan kelebihan. Pada suction drain, seroma akan dihisap dengan pemberian tekanan negatif, sehingga cairan akan keluar terus-menerus. Kerugiannya, drain ini mempunyai diameter kecil sehingga sering tersumbat. Drain pasif hanya mengandalkan prinsip gravitasi dan dapat digunakan drain dengan diameter lebih besar. Pemakaian suction drain pertama kali diperkenalkan pada tahun 1947, penggunaan drain telah dibuktikan bermanfaat mengeluarkan seroma dan meminimalkan dead space. ${ }^{3}$

Lama pemakaian drain juga masih diperdebatkan. Pada beberapa penelitian, insiden seroma cukup tinggi terutama jika tidak dipasang drain. Di lain pihak, cairan seroma akan terus terbentuk walaupun setelah drain dibuka. Hal ini dapat

\section{Tabel 1 Karakteristik sampel penelitian}

\begin{tabular}{lcc}
\hline Karakteristik & Jumlah & Persentase \\
\hline Umur & & \\
$\quad \leq 40$ Tahun & 6 & $16 \%$ \\
ahun & 26 & $72 \%$ \\
$\quad$ 60 tahun & 4 & $12 \%$ \\
Lama Pemakaian Drain & & \\
$\quad \leq 3$ Hari & 19 & $53 \%$ \\
$\quad>3$ hari & 17 & $47 \%$ \\
Lama Rawat Inap & & \\
$\quad \leq 5$ Hari & 19 & $53 \%$ \\
$>5$ hari & 17 & $47 \%$ \\
\hline
\end{tabular}

dilihat dari adanya seroma di daerah aksila, dapat dideteksi melalui pemeriksaan fisik atau dengan pemeriksaan penunjang seperti ultrasonografi (USG). Jika volume drain dipertahankan hingga kurang dari 30-50 ml/hari akan meningkatkan durasi perawatan di rumah sakit mencapai 6-8 hari perawatan dan risiko infeksi oleh migrasi kuman retrograd. ${ }^{4}$

Merujuk masalah tersebut diatas perlu dilakukan pengkajian lebih mendalam tentang cost-effectiveness pada pengangkatan drain kurang dari tiga hari dengan lebih dari tiga hari, pada pasien LABC pasca tindakan MRM.

\section{METODE}

Penelitian ini merupakan penelitian cost-effectivness analisis menggunakan decision tree, dengan rancangan metode penelitian analytic cross sectional. Pengambilan data dilakukan secara retrospektif dengan membandingkan direct medical cost (biaya medis langsung) untuk mengevaluasi perbedaaan cost-effectiveness pengangkatan drain kurang dari tiga hari dan lebih dari tiga hari pada modified radical mastectomy (MRM). Hasil penelitian dianalisis dengan analisis deskriptif. Cost-Effectiveness Analysis (CEA) dihitung dengan menggunakan rumus Average Cost-Effectiveness Ratio (ACER) berdasarkan jumlah biaya perawatan dan efektivitas

\section{HASIL PENELITIAN}

Selama periode Juli 2018 sampai dengan Desember 2018, tercatat 49 pasien dengan diagnosa LABC menjalani operasi MRM di Instalasi Bedah Sentral RSUP Sanglah, Denpasar. Dari 49 pasien tersebut terdapat 7 pasien dengan perawatan diluar kelas III. Dari 42 pasien, 6 pasien terdiagnosa diabetes mellitus, sehingga terdapat 36 pasien yang memenuhi kriteria inklusi dan ekslusi. Sampel dipilih dengan cara consecutive sampling, sampel dimasukkan kedalam kelompok dengan pengangkatan drain $\leq 3$ hari dengan pengangkatan drain $>3$ hari sampai jumlah masing masing sampel terpenuhi.

Dikumpulkan 36 sampel yang memenuhi kriteria ekslusi dan inklusi, terdiri dari 19 sampel pada kelompok dengan pengangkatan drain $\leq 3$ hari, dan 17 sampel pada kelompok dengan pengangkatan drain $>3$ hari. Distribusi sampel berdasarkan usia dapat dilihat pada tabel 1. Analisis biaya pada pengangkatan drain yang kurang dari tiga hari menunjukkan rerata direct medical cost pasien adalah Rp. 700,578,00 (Tabel 2). Sedangkan untuk pasien dengan pengangkatan drain lebih dari toga hari menunjukkan direct medical cost sebesar Rp. 981.000,00 (Tabel 3). 
Tabel 2 Direct medical cost pasien dengan penggunaan drain $\leq \mathbf{3}$ hari

\begin{tabular}{|c|c|c|c|c|c|}
\hline No & Nama & Lama rawat inap (hari) & Biaya pengobatan (Rp.) & Biaya visite dokter (Rp.) & Total biaya (Rp.) \\
\hline 1 & $\mathrm{RD}$ & 5 & $675,000,00$ & $90,000,00$ & $765,000,00$ \\
\hline 2 & MA & 6 & $675,000,00$ & $90,000,00$ & $765,000,00$ \\
\hline 3 & WS & 7 & $675,000,00$ & $90,000,00$ & $765,000,00$ \\
\hline 4 & $\mathrm{KH}$ & 6 & $675,000,00$ & $90,000,00$ & $765,000,00$ \\
\hline 5 & $\mathrm{SH}$ & 7 & $540,000,00$ & $72,000,00$ & $612,000,00$ \\
\hline 6 & $\mathrm{AM}$ & 7 & $540,000,00$ & $72,000,00$ & $612,000,00$ \\
\hline 7 & NM & 7 & $675,000,00$ & $90,000,00$ & $765,000,00$ \\
\hline 8 & NK & 7 & $675,000,00$ & $90,000,00$ & $765,000,00$ \\
\hline 9 & KG & 6 & $675,000,00$ & $90,000,00$ & $765,000,00$ \\
\hline 10 & SP & 6 & $540,000,00$ & $72,000,00$ & $612,000,00$ \\
\hline 11 & KA & 5 & $540,000,00$ & $72,000,00$ & $612,000,00$ \\
\hline 12 & SA & 6 & $675,000,00$ & $90,000,00$ & $765,000,00$ \\
\hline 13 & $\mathrm{NN}$ & 7 & $540,000,00$ & $72,000,00$ & $612,000,00$ \\
\hline 14 & NL & 6 & $540,000,00$ & $72,000,00$ & $612,000,00$ \\
\hline 15 & NS & 7 & $540,000,00$ & $72,000,00$ & $612,000,00$ \\
\hline 16 & $\mathrm{Nn}$ & 7 & $675,000,00$ & $90,000,00$ & $765,000,00$ \\
\hline 17 & $\mathrm{Al}$ & 7 & $675,000,00$ & $90,000,00$ & $765,000,00$ \\
\hline 18 & NS & 5 & $675,000,00$ & $90,000,00$ & $765,000,00$ \\
\hline 19 & LS & 4 & $540,000,00$ & $72,000,00$ & $612,000,00$ \\
\hline \multicolumn{5}{|c|}{ Total direct medical cost } & Rp. $13,311,000,00$ \\
\hline \multicolumn{5}{|c|}{ Rarta-rata direct medical cost } & Rp. $700,578,00$ \\
\hline
\end{tabular}

Tabel 3 Direct medical cost pasien dengan penggunaan drain $>3$ hari

\begin{tabular}{|c|c|c|c|c|c|}
\hline No & Nama & Lama rawat inap (hari) & Biaya pengobatan (Rp.) & Biaya visite dokter (Rp.) & Total biaya (Rp.) \\
\hline 1 & WS & 5 & $675,000,00$ & $90,000,00$ & $765,000,00$ \\
\hline 2 & NK & 6 & $810,000,00$ & $108,000,00$ & $918,000,00$ \\
\hline 3 & NW & 7 & $945,000,00$ & $126,000,00$ & $1,071,000,00$ \\
\hline 4 & LP & 6 & $810,000,00$ & $108,000,00$ & $918,000,00$ \\
\hline 5 & SL & 7 & $945,000,00$ & $126,000,00$ & $1,071,000,00$ \\
\hline 6 & $\mathrm{AA}$ & 7 & $945,000,00$ & $126,000,00$ & $1,071,000,00$ \\
\hline 7 & SS & 7 & $945,000,00$ & $126,000,00$ & $1,071,000,00$ \\
\hline 8 & NS & 7 & $945,000,00$ & $126,000,00$ & $1,071,000,00$ \\
\hline 9 & NL & 6 & $810,000,00$ & $108,000,00$ & $918,000,00$ \\
\hline 10 & $\mathrm{PP}$ & 6 & $810,000,00$ & $108,000,00$ & $918,000,00$ \\
\hline 11 & $\mathrm{NM}$ & 5 & $675,000,00$ & $90,000,00$ & $765,000,00$ \\
\hline 12 & NW & 6 & $810,000,00$ & $108,000,00$ & $918,000,00$ \\
\hline 13 & NG & 7 & $945,000,00$ & $126,000,00$ & $1,071,000,00$ \\
\hline 14 & NK & 6 & $810,000,00$ & $108,000,00$ & $918,000,00$ \\
\hline 15 & SM & 7 & $945,000,00$ & $126,000,00$ & $1,071,000,00$ \\
\hline 16 & $\mathrm{LN}$ & 7 & $945,000,00$ & $126,000,00$ & $1,071,000,00$ \\
\hline 17 & $\mathrm{KH}$ & 7 & $945,000,00$ & $126,000,00$ & $1,071,000,00$ \\
\hline \multicolumn{5}{|c|}{ Total direct medical cost } & Rp. $16,677,000,00$ \\
\hline \multicolumn{5}{|c|}{ Rarta-rata direct medical cost } & Rp. $981.000,00$ \\
\hline
\end{tabular}


Tabel 4 Perhitungan ACER

\begin{tabular}{|c|c|c|c|}
\hline Macam biaya & Pengangkatan drain $\leq \mathbf{3}$ hari & Pengangkatan drain $>3$ hari & Selisih \\
\hline Rata-rata direct medical cost (B) & Rp. $700,578,00$ & Rp. $981,000,00$ & Rp. $280,422,00$ \\
\hline Rata-rata lama hari rawat inap/efektifitas (E) & 5 hari & 7 hari & 2 hari \\
\hline $\operatorname{ACER}(B / E)$ & RP. $140,115,00$ & Rp. $142,714,00$ & Rp. $2,599,00$ \\
\hline
\end{tabular}

Efektivitas kurang baik dengan
biaya lebih mahal

Gambar 5 Empat kuadran efektivitas biaya

Perhitungan ACER, pasien dengan pengangka$\tan$ drain $\leq 3$ hari dengan rata-rata lama hari rawat inap selama 5 hari sebesar Rp, 140.115,00. Pada pasien dengan pengangkatan drain $>3$ hari dengan rata-rata lama hari rawat inap selama 7 hari sebesar 142.714,00 (Tabel 4).

\section{PEMBAHASAN}

Secara umum di bidang kesehatan, biaya merupakan hal yang penting untuk dipertimbangkan. Pelaku di bidang kesehatan dituntut untuk menyediakan pelayanan kesehatan yang berkualitas dengan biaya serendah mungkin (cost containment). ${ }^{2,3}$

Konsep yang menyatakan bahwa biaya yang diperlukan untuk pelayanan kesehatan sangat besar, bukanlah merupakan hal yang baru. Diseluruh dunia, pemerintahnya selalu berusaha untuk mengendalikan biaya yang dihabiskan oleh pelayanan kesehatan. Hal ini menyebabkan biaya rumah sakit, biaya penggunaan obat-obatan serta pembayaran staf medis dan paramedis perlu dievaluasi dengan seksama. ${ }^{5}$

Indonesia telah memasuki era pelayanan kesehatan dengan managed care system melalui BPJS kesehatan (Ekahospital, Evaluasi Mutu Pelayanan Kesehatan dalam Managed Care). Menurut PT Askes dalam persiapan BPJS, managed care system adalah suatu sistem dimana pelayanan kesehatan dan pembiayaan kesehatan diselenggarakan secara tersinkronisasi dalam kerangka kendali mutu dan biaya, sehingga menghasilkan pelayanan kesehatan yang bermutu dan dengan biaya yang efisien. Pelaksanaan BPJS menggunakan konsep "gatekeeper", quality assurance, dengan sistem rujukan yang komprehensif. ${ }^{6}$

Dari data pasien LABC pasca operasi MRM yang terkumpul di RSUP sanglah selama periode 1 Juli - 31 Desember 2018 didapatkan 36 pasien rawat inap. Pasien dengan pengangkatan drain $\leq 3$ hari memiliki rata rata hari rawat inap yang lebih baik dibandingkan dengan pengangkatan drain $>3$ hari, dengan rata rata 5 hari rawat inap.

Dari hasil total direct medical cost, pasien dengan pengangkatan drain $\leq 3$ hari $(\mathrm{Rp}, 700.578,00)$ masih lebih kecil dibandingkan dengan pasien dengan pengangkatan drain $>3$ hari. Pada tabel 5.4 didapatkan hasil dari perhitungan direct medical cost per pasien yang dibagi rata-rata lama hari rawat inap sehingga didapatkan ACER dari penggunaan drain $\leq 3$ hari yaitu $\mathrm{Rp}$ 140.115,00/hari sedangkan ACER dari penggunaan drain $>3$ hari yaitu Rp, 142.714,00/hari.

Dalam ACER semakin kecil nilai ACER maka tindakan tersebut semakin cost effective. Sehingga dapat disimpulkan bahwa pengangkatan drain $\leq 3$ hari lebih cost effective dibandingkan $>3$ hari pada pasien LABC pasca MRM.

Berdasarkan hasil yang didapatkan maka kedua alternatif terapi tersebut dapat dimasukkan ke dalam sumbu $\times$ dan y berdasarkan perbandingan biaya dan efektivitas terapi kemudian ditarik kesimpulan. Perbandingan tersebut dapat dilihat pada gambar 5.

Kuadran efektivitas biaya adalah metode umum untuk merepresentasikan data dari analisis keefektifan biaya atau utilitas biaya. Seringkali dalam perawatan kesehatan, poinnya jatuh di kuadran kanan atas, yang menunjukkan peningkatan hasil tetapi dengan biaya yang lebih tinggi. Ketika sebuah terapi jatuh di kuadran kanan bawah, biaya yang lebih rendah dikaitkan dengan hasil yang lebih baik, yang ditetapkan sebagai terapi dominan atau "menang-menang" yang selalu ingin diadopsi oleh pembuat keputusan. Sebaliknya, ketika terapi jatuh ke kuadran kiri atas, biaya yang lebih tinggi dikaitkan dengan hasil yang lebih buruk, dan terapi dominasi semacam itu tidak pernah menarik bagi para pembuat keputusan. ${ }^{7}$

Sesuai dengan diagram efektivitas biaya, pengangkatan drain $\leq 3$ hari terdapat pada kuadran kanan bawah yang artinya efektifitas lebih baik dengan biaya lebih murah. 


\section{SIMPULAN}

Pada penelitian ini didapatkan pasien dengan pengangkatan drain $\leq 3$ hari memiliki cost-effectiveness lebih baik dibandingkan dengan pengangkatan drain $>3$ hari. Pasien dengan pengangkatan drain $\leq 3$ hari memiliki length of stay lebih baik dengan rata -rata 5 hari rawat inap dibandingkan dengan pengangkatan drain $>3$ hari dengan rata-rata 7 hari rawat inap.

\section{KONFLIK KEPENTINGAN}

Penulis menyatakan tidak terdapat konflik kepentingan terkait publikasi dari penelitian ini.

\section{PENDANAAN}

Penelitian ini tidak mendapatkan bantuan dana dari pemerintah ataupun sector swasta lainnya.

\section{ETIKA DALAM PENELITIAN}

Penelitian ini telah mendapatkan persetujuan dari Komite Etik Fakultas Kedokteran Universitas Udayana/RSUP Sanglah Denpasar, dengan nomer referensi: LB.02.01/XIV.2.2.1/13986/2019.

\section{DAFTAR PUSTAKA}

1. Shah $\mathrm{SH}$, et al. Modified radical mastectomy; Morbidity during early postoperative period. The Prof J Onc. 2004;41:122-129.

2. Kuroi K, Sjimozuma K, Taguchi T, Imai H, Yamashiro H, Ohsumi S, et al. Evidence based risk factors for seroma in breast surgery. Japan J Chin Oncol. 2006;36:197-206.

3. Hashemi E, Kaviani A, et al. Seroma formation after surgey for breast cancer. World Journal of Surgical Oncology. 2004;2:44.

4. Vitug FA, et al. Complications in Breast Surgery. Surgical Clinics of North America. 2007;87(2):431-51.

5. Edin R, Round J, Hulme C, et al. Cost effectiveness analysis and efficient use of the pharmaceutical budget: the key role of clinical pharmacologist: Br J Clin Pharmacol. 2010;70(3):350-5.

6. BPJS Kesehatan Indonesia. PT. Askes Persiapan BPJS Kesehatan. Diunduh dari: http://www.djsn.go.id/PT.\%20 Askes_Persiapan\%20BPJS\%20Kesehatan.pdf tanggal 1 Januari 2019.

7. Dukhovny J, et al. Economic evaluation of cancer drugs: using clinical trial and real word data. New York: Black Well Publishig; 2011.

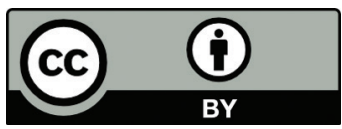

This work is licensed under a Creative Commons Attribution 